\title{
Risk of Burnout in Front-Line Health Care Workers When Combating Covid-19: A Prospective Cross-Sectional Study
}

\author{
Adde Midian Putra Chafid ${ }^{1}$, Nancy Margarita Rehatta ${ }^{2 *}$, Elizeus Hanindito ${ }^{3}$, and \\ Margarita Maria Maramis ${ }^{4}$
}

\author{
${ }^{1}$ Department of Specialist Anesthesiologya and Intensive Therapy, Faculty of Medicine (60132), \\ Universitas Airlangga, Indonesia \\ 2,3,4Faculty of Medicine (60132), Universitas Airlangga, Indonesia \\ Email: ${ }^{1}$ unairadde@gmail.com; 2margaritarehatta@gmail.com; ${ }^{3}$ elizeushanindito@gmail.com; \\ ${ }^{4}$ margaritamaramis61@gmail.com
}

*Corresponding author details: Nancy Margarita Rehatta; margaritarehatta@gmail.com

\begin{abstract}
Specialist resident education is a level of professional development to improve the professional qualifications of specialist doctors, which is a tough and stressful process. Medical personnel who treat patients exposed to COVID19 experience burnout. This study was to determine the risk of burnout in anesthesiology residents and intensive care as a frontline during the COVID-19 pandemic era. The research design was an observational analytic study that was cross-sectional towards residents who served in the Special Isolation Room of Dr. Soetomo Surabaya. The sample in this study used total sampling and obtained 35 respondents. The statistical test used multiple linear regression. Each research subject was given an online Maslach Burnout Inventory (MBI) questionnaire assessment of the Maslach Burnout Inventory (MBI) questionnaire given before serving in the Special Isolation Room (PreRIK), post-assignment (Post-RIK) in the Special Isolation Room and post Self Isolation (Post-ISOMAN). Burnout study in resident Anesthesiology and Intensive Care at Dr. Soetomo in the prevention of COVID-19 in Pre-RIK showed that 3 people had a burnout of $9.37 \%$ and 32 people had no burnout at $90.63 \%$. At Post-RIK there were 3 burnouts (9.37\%) and 32 people (90.63\%) without burnout. In Post-ISOMAN there was 1 burnout (2.85\%) and without burnout of 34 people (97.15\%). In the study, it was found that resident receipts in 2019 experienced more burnout, compared to resident at the end of the year.
\end{abstract}

Keywords: anesthesiologist resident; burnout; COVID-19; MBI

\section{INTRODUCTION}

Residents who undergo education in developing countries experience more severe conditions than in developed countries. Physician burnout has reached epidemic levels with an estimated prevalence of between $30 \%$ and over $54 \%$. Burnout is a consequence of prolonged and excessive stress, which occurs when the ability is deemed unable to meet demands (Barello et al., 2020). The subsequent burnout is characterized by a triad of emotional exhaustion, decreased sense of accomplishment, and depersonalization. Compared with the general population, physicians had twice the risk of burnout, and 1.4-2.3 times the relative risk of suicide for male and female physicians, respectively (Sumner \& Kinsella, 2021).

Compared with other physicians, anesthesiologists have been to have higher risk run into burnout, substance abuse, and death from suicide. What is more worrying is that the risk of burnout was highest during the resident's education. (Spence et al., 2018). Compared with anesthesiologists, anesthetist residents had twice the incidence of substance abuse and three times the incidence of suicide. (Fry et al., 2015)
This has significant implications not only for the personal well-being and the next generation of professional anesthesiologists but also for patient care and safety. (De Oliveira et al., 2013)

The world was shocked by the COVID-19 outbreak, namely Coronavirus disease 2019, which was first announced in Wuhan, China on November 17, 2019, then spread to various countries in the world (Sultana et al., 2020). On March 11, 2020, WHO declared COVID-19 a pandemic. In Indonesia, COVID-19 was first discovered and officially announced by the President of the Republic of Indonesia on March 2, 2020, and since then the coronavirus has spread to various provinces in Indonesia (Prabowo et al., 2020).

Some of the factors that influence burnout among residents include gender, age, marital status, level of education, personality, and occupational stressors (Sumner \& Kinsella, 2021). Based on the background above, this study has a purpose to observe risk factors of burnout toward front-line health workers to combat COVID-19 in Dr. Soetomo Hospital. The practical implication of this study is to help in giving an evaluation of burnout condition in front-line health workers so that it will avoid any further victims of health workers ' death. 


\section{MATERIALS AND METHOD}

The study design is a cross-sectional observational analytic study. To analyze burnout, it was measured using the Maslach Burnout Inventory, as well as with Tempa T research in the Isolation Room Special Hospital Dr. Soetomo Surabaya.

The research was conducted from July to October 2020, after approval by the ethics committee of Hospital Dr. Soetomo Surabaya. The population for this study are residents of Anesthesiology and Intensive Therapy that work in the Isolation Room Special Hospital, Dr. Soetomo Surabaya (Duan et al., 2019).

The subjects in this study were residents of Anesthesiology and Intensive Therapy FK Unair Dr. Soetomo Surabaya, who was willing to be a respondent. Each research subject was given an online questionnaire on characteristic data, the Maslach Burnout Inventory (MBI) questionnaire to determine the incidence and rate of burnout. Besides, research subjects will also fill out a questionnaire for Personality Types A and B from (Matsuo et al., 2020).

The sample size in this study is the populations size minus one (1). In the process of removing one sample, the simple random sampling technique was used. The sample size in this study 35 (Wardhana, 2020). Criteria for the inclusion of a sample that is no excuse to get information on research and research purposes (listed in the information for consent) and are willing to follow (signed informed consent). Sample were also included residents of Anesthesiologia and Intensive Therapy which in charge of a special isolation room Hospital Dr. Soetomo Surabaya (Tziomalos et al., 2017).

This study used participants of PPDS Anesthesiology and Intensive Therapy at the Faculty of Medicine, Airlangga University, Dr. Soetomo Surabaya totaling 35 people as research subjects. Each research subject is a resident of PPDS Anesthesiology and Intensive Therapy FK Unair RSUD Dr. Soetomo who served in the Isolation Room Special divided into 3 shifts where $\mathrm{s} h$ if $\mathrm{t}$ first consists of 3 PPDS, each $s \mathrm{~h}$ if $y$ guard has a duration of action for 12 hours, then rest 24 hours, after 2 weeks of work to isolate independently during 1 week and do a swab. If the result is negative, the resident returns to the general stage (Movlavi \& Salehi, 2019).

Each research subject was given an online questionnaire on characteristic data, the Maslach Burnout Inventory (MBI) questionnaire to determine the incidence and level of burnout and salivary cortical sampling in the morning when he was assigned to a special isolation room.

The Maslach Burnout Inventory(MBI) questionnaire assess ment was given before serving in the Special Isolation Room (Pre-RIK), post-assignment (Post-RIK) in the Special Isolation Room, and after the Independent Isolation (PostISOMAN) (Gu et al., 2019).

The dependent variable for this study is burnout. The independent variables are Gender, Age, Marital Status, Level of Education, Personality Job Stressors, resilience,

and kopin. Data were collected and processed in the form of distribution tables and then analyzed using the Multiple Linear Regression statistical test (Żemojtel-Piotrowska et al., 2018).

\section{RESULT OF THE STUDY}

Based on socio-demographic data, it is known that the research subjects were on average 30 years old, of which the youngest was 24 years and the oldest was 36 years. The male gender in the research subject amounted to 30 people or $85.7 \%$ and 5 women or $14.3 \%$. Marital status obtained 24 people or $68.6 \%$ and subjects who were single were 11 people or $31.4 \%$.

TABLE 1: Socio-Demographic Overview of Research Subjects

\begin{tabular}{|c|c|}
\hline Variable & N=35 \\
\hline \multicolumn{2}{|c|}{ Marital status } \\
\hline Single & $11(31.4 \%)$ \\
\hline Married & $24(68.6 \%)$ \\
\hline
\end{tabular}

TABLE 2: Description of Total MBI A, B, and C in the PreRIK, Post-RIK and Post-ISOMAN groups

\begin{tabular}{|l|c|c|c|}
\hline \multirow{2}{*}{ Variable } & \multicolumn{3}{|c|}{ RIK Task Stage } \\
\cline { 2 - 4 } & $\begin{array}{c}\text { Pre-RIK } \\
\text { N = 35 }\end{array}$ & $\begin{array}{c}\text { Post-RIK } \\
\text { N = 35 }\end{array}$ & $\begin{array}{c}\text { Post- } \\
\text { ISOMAN } \\
\text { N = 35 }\end{array}$ \\
\hline Total MBI A & & & \\
\hline $\begin{array}{l}\text { Low levels of } \\
\text { emotional } \\
\text { exhaustion }\end{array}$ & $\begin{array}{c}25 \\
(71.4 \%)\end{array}$ & $\begin{array}{c}28 \\
(80 \%)\end{array}$ & $\begin{array}{c}31 \\
(88.5 \%)\end{array}$ \\
\hline $\begin{array}{l}\text { Moderate } \\
\text { emotional } \\
\text { exhaustion }\end{array}$ & $\begin{array}{c}7 \\
(20 \%)\end{array}$ & $\begin{array}{c}4 \\
(11.4 \%)\end{array}$ & $\begin{array}{c}2 \\
(5.7 \%)\end{array}$ \\
\hline $\begin{array}{l}\text { High levels of } \\
\text { exotional }\end{array}$ & $\begin{array}{c}3 \\
(8.5 \%)\end{array}$ & $\begin{array}{c}3 \\
(8.5 \%)\end{array}$ & $\begin{array}{c}2 \\
(5.7 \%)\end{array}$ \\
\hline Total MBI B & 11 & 14 & 12 \\
\hline $\begin{array}{l}\text { Low level of work } \\
\text { fatigue }\end{array}$ & $(31.4 \%)$ & $(40.0 \%)$ & $(34.2 \%)$ \\
\hline $\begin{array}{l}\text { Moderate fatigue } \\
(40.0 \%)\end{array}$ & $\begin{array}{c}13 \\
(37.1 \%)\end{array}$ & $\begin{array}{c}15 \\
(42.8 \%)\end{array}$ \\
\hline $\begin{array}{l}\text { High level of work } \\
\text { fatigue }\end{array}$ & $\begin{array}{c}10 \\
(28.5 \%)\end{array}$ & $\begin{array}{c}8 \\
(22.8 \%)\end{array}$ & $\begin{array}{c}8 \\
(22.8 \%)\end{array}$ \\
\hline Total MBI C & $\begin{array}{c}23 \\
\text { Moderate personal } \\
\text { accomplishments }\end{array}$ & $(25.7 \%)$ & $\begin{array}{c}21 \\
(22.8 \%)\end{array}$ \\
\hline $\begin{array}{l}\text { High personal } \\
\text { achievement }\end{array}$ & $(17.1 \%)$ & $(11,4 \%)$ & $\begin{array}{c}7 \\
(20.0 \%)\end{array}$ \\
\hline
\end{tabular}

The results of MBI part A in pre-RIK for the low category were 25 people or $71 \%$, for the moderate category it was 7 people or $20 \%$ and the high category was 3 people or $8.5 \%$. In post-RIK, the results obtained for the low category were 28 people or $80 \%$, for the moderate category it was 4 people or $11.4 \%$, and for the high category it was 3 people or $8.5 \%$. In Post-ISOMAN, the results obtained for the low category were 31 people or $88.5 \%$, for the medium category were 2 people or $5.7 \%$, and for the high category were 2 people or $5.7 \%$.

The results of the assessment of the MBI questionnaire section B showed that the Pre-RIK results were obtained for the low category of 11 people or $31.4 \%$, the medium category was 14 people or $40 \%$, and the high category 10 people or $28.5 \%$. In the Post-RIK stage, the results obtained for the low category were 14 people or $40 \%$, the medium category was 13 people or $37.1 \%$ and the high category was 8 people or $22.8 \%$. In the Post-ISOMAN stage, the results obtained for the low category were 12 people or $34.2 \%$, the medium category was 15 people or $42.8 \%$ and the high category was 8 people or $22.8 \%$. 
The results of the MBI section $C$ in the Pre-RIK showed that the low category was 20 people or $57.1 \%$, the moderate category was 9 people or $25.7 \%$, and the high category was 6 people or $17.1 \%$. Post-RIK personal achievement results were obtained in the low category of 23 people or $65.7 \%$, the medium category of 8 people or $22.8 \%$, and the high category of 4 people or $22.8 \%$. The results of PostISOMAN's achievement showed that the low category was 21 people $60 \%$, the moderate category was 7 people or $20 \%$, and the high category was 7 people or $20 \%$.

TABLE 3: Description of PPDS Stressors on Burnout in the Pre-RIK Stage

\begin{tabular}{|l|c|c|}
\hline \multirow{2}{*}{ Variable } & \multicolumn{2}{|c|}{ Impression } \\
\cline { 2 - 3 } & Burnout & Not Burnout \\
\hline Job Stressor & & $14(87.5 \%)$ \\
\hline $\begin{array}{l}\text { Reporting \& } \\
\text { Communication } \\
(\mathrm{N}=16)\end{array}$ & $2(14.3 \%)$ & $9(90.0 \%)$ \\
\hline CRRT (N = 9) & $1(10.0 \%)$ & $1(100 \%)$ \\
\hline $\begin{array}{l}\text { Echocardiography } \\
(\mathrm{N}=1)\end{array}$ & $0(0 \%)$ & $4(100 \%)$ \\
\hline Intubation (N = 4) & $0(100 \%)$ & $1(100 \%)$ \\
\hline ABP (N = 1) & $0(0 \%)$ & $1(100 \%)$ \\
\hline Using Hazmat (N=1) & $0(100 \%)$ & $1(100 \%)$ \\
\hline Heat and Well (N =1) & $0(0 \%)$ & $1(100 \%)$ \\
\hline None (N = 1) & $0(0 \%)$ & \\
\hline
\end{tabular}

Data stressor PPDS against burnout at Pre-RIK obtained the data which the stressor reporting and communications reported 16 PPDS in which 14 or $87.5 \%$ of people in the group do not burnout and 2 or $14.3 \%$ in the burnout, followed by CRRT in the group do not burnout as much 9 people, Echocardiography 1 person, intubation 4 people, using hazmat 1 person, heat and stifling 1 person, and all reported in the no burnout group.

In the image data stressor PPDS against burnout on the Post-CMP obtained the data which the stressor reporting and communications reported 16 people of which 14 or $87.5 \%$ of people in the group do not burnout and 2 or $14.3 \%$ in the burnout, followed by CRRT in the group do not burnout as much 9 people, Echocardiography 1 person, intubation 4 people, using hazmat 1 person, heat and stifling 1 person, and all reported in the no burnout group.

In the PPDS stressor image data on burnout in Post-ISOMAN, data was obtained where reporting and communication stressors were reported by 16 people, followed by CRRT in the non- burnout group of 10 people, Echocardiography 1 person, intubation 4 people, using 1 hazmat 1 person, heat and 1 people, and everything was reported in the no burnout group.

TABLE 4: Overview of PPDS Stressors on Burnout in the Post-RIK Stage

\begin{tabular}{|l|c|c|}
\hline \multirow{2}{*}{\multicolumn{1}{|c|}{ Variable }} & \multicolumn{2}{c|}{ Impression } \\
\cline { 2 - 3 } & Burnout & Not Burnout \\
\hline Job Stressor & & $14(87.5 \%)$ \\
\hline $\begin{array}{l}\text { Reporting \& } \\
\text { Communication } \\
(\mathrm{N}=16)\end{array}$ & $2(14.3 \%)$ & $9(90.0 \%)$ \\
\hline CRRT (N = 9) & $1(10.0 \%)$ & $1(100 \%)$ \\
\hline $\begin{array}{l}\text { Echocardiography } \\
(\mathrm{N}=1)\end{array}$ & $0(0 \%)$ & \\
\hline
\end{tabular}

\begin{tabular}{|l|c|c|}
\hline Intubation $(\mathrm{N}=4)$ & $0(100 \%)$ & $4(100 \%)$ \\
\hline ABP $(\mathrm{N}=1)$ & $0(0 \%)$ & $1(100 \%)$ \\
\hline Using Hazmat $(\mathrm{N}=1)$ & $0(100 \%)$ & $1(100 \%)$ \\
\hline Heat and Well $(\mathrm{N}=1)$ & $0(0 \%)$ & $1(100 \%)$ \\
\hline None $(\mathrm{N}=1)$ & $0(0 \%)$ & $1(100 \%)$ \\
\hline
\end{tabular}

TABLE 5: Overview of PPDS Stressors on Burnout in the Post-ISOMAN Stage

\begin{tabular}{|l|c|c|}
\hline \multirow{2}{*}{\multicolumn{1}{|c|}{ Variable }} & \multicolumn{2}{|c|}{ Impression } \\
\cline { 2 - 3 } & Burnout & Not Burnout \\
\hline Job Stressor & & $16(100 \%)$ \\
\hline $\begin{array}{l}\text { Reporting \& } \\
\text { Communication } \\
\mathrm{N}=16)\end{array}$ & $0(0 \%)$ & $10(100 \%)$ \\
\hline CRRT (N = 9) & $0(0.0 \%)$ & $1(100 \%)$ \\
\hline $\begin{array}{l}\text { Echocardiography } \\
(\mathrm{N}=1)\end{array}$ & $0(0 \%)$ & $4(100 \%)$ \\
\hline Intubation (N =4) & $0(00 \%)$ & $1(100 \%)$ \\
\hline ABP (N = 1) & $0(0 \%)$ & $1(100 \%)$ \\
\hline Using Hazmat (N =1) & $0(00 \%)$ & $1(100 \%)$ \\
\hline Heat and Well (N =1) & $0(0 \%)$ & $1(100 \%)$ \\
\hline None (N =1) & $0(0 \%)$ & \\
\hline
\end{tabular}

In the data analysis, the relationship between the characteristics of the subjects that include gender, age, marital status, years of acceptance PPDS, personality, work stressors, on the incidence of burnout in the PostISOMAN obtained relationship between duration of Education against burnout Post-ISOMAN, those in first year (2019) experienced more burnout, compared to the last year.

TABLE 6: Relationship of Subject Characteristics to Burnout Incidence in Pre-RIK

\begin{tabular}{|c|c|c|c|}
\hline \multirow{2}{*}{ Variable } & \multicolumn{3}{|c|}{ Impression } \\
\hline & Burnout & $\begin{array}{c}\text { Not } \\
\text { Burnout }\end{array}$ & p-Value \\
\hline Gender & & & 1,000 \\
\hline Age & & & 0.574 \\
\hline Marital status & & & 0.998 \\
\hline \multicolumn{4}{|l|}{$\begin{array}{l}\text { PPDS Receipt } \\
\text { Year }\end{array}$} \\
\hline 2019 year & $\begin{array}{c}0 \\
(0.0 \%)\end{array}$ & $\begin{array}{c}14 \\
(100 \%)\end{array}$ & 0.997 \\
\hline 2018 year & $\begin{array}{c}1 \\
(10.0 \%) \\
\end{array}$ & $\begin{array}{c}9 \\
(90.0 \%)\end{array}$ & 0.997 \\
\hline 2017 year & $\begin{array}{c}1 \\
(25.0 \%) \\
\end{array}$ & $\begin{array}{c}3 \\
(75.0 \%) \\
\end{array}$ & 0.997 \\
\hline 2016 year & $\begin{array}{c}1 \\
(14.3 \%) \\
\end{array}$ & $\begin{array}{c}6 \\
(85.7 \%) \\
\end{array}$ & 0.997 \\
\hline Personality & & & 0.996 \\
\hline \multicolumn{4}{|l|}{ Job Stressor } \\
\hline $\begin{array}{l}\text { Reporting \& } \\
\text { Communication } \\
(\mathrm{N}=16)\end{array}$ & $\begin{array}{c}2 \\
(14.3 \%)\end{array}$ & $\begin{array}{c}14 \\
(87.5 \%)\end{array}$ & 1,000 \\
\hline $\begin{array}{l}\text { CRRT } \\
(\mathrm{N}=9) \\
\end{array}$ & $\begin{array}{c}1 \\
(10.0 \%) \\
\end{array}$ & $\begin{array}{c}9 \\
(90.0 \%)\end{array}$ & 1,000 \\
\hline $\begin{array}{l}\text { Echocardiography } \\
(\mathrm{N}=1)\end{array}$ & $\begin{array}{c}0 \\
(0 \%)\end{array}$ & $\begin{array}{c}1 \\
(100 \%)\end{array}$ & 1,000 \\
\hline
\end{tabular}




\begin{tabular}{|l|c|c|c|}
\hline $\begin{array}{l}\text { Intubation } \\
(\mathrm{N}=4)\end{array}$ & $\begin{array}{c}0 \\
(100 \%)\end{array}$ & $\begin{array}{c}4 \\
(100 \%)\end{array}$ & 1,000 \\
\hline $\begin{array}{l}\mathrm{ABP} \\
(\mathrm{N}=1)\end{array}$ & $\begin{array}{c}0 \\
(0 \%)\end{array}$ & $\begin{array}{c}1 \\
(100 \%)\end{array}$ & 1,000 \\
\hline $\begin{array}{l}\text { Using Hazmat } \\
(\mathrm{N}=1)\end{array}$ & $\begin{array}{c}0 \\
(100 \%)\end{array}$ & $\begin{array}{c}1 \\
(100 \%)\end{array}$ & 1,000 \\
\hline $\begin{array}{l}\text { Heat and Well } \\
(\mathrm{N}=1)\end{array}$ & $\begin{array}{c}0 \\
(0 \%)\end{array}$ & $\begin{array}{c}1 \\
(100 \%)\end{array}$ & 1,000 \\
\hline
\end{tabular}

TABLE 7: Relation of Subject Characteristics to Burnout Incidence in Post-RIK

\begin{tabular}{|c|c|c|c|}
\hline \multirow[b]{2}{*}{ Variable } & \multicolumn{3}{|c|}{ Impression } \\
\hline & Burnout & $\begin{array}{c}\text { Not } \\
\text { Burnout }\end{array}$ & p-Value \\
\hline Gender & & & 0.998 \\
\hline Age & & & 1,000 \\
\hline Marital status & & & 0.999 \\
\hline \multicolumn{4}{|l|}{$\begin{array}{l}\text { PPDS Receipt } \\
\text { Year }\end{array}$} \\
\hline 2019 year & $\begin{array}{c}0 \\
(0.0 \%) \\
\end{array}$ & $\begin{array}{c}14 \\
(100 \%) \\
\end{array}$ & 0.998 \\
\hline 2018 year & $\begin{array}{c}1 \\
(10.0 \%) \\
\end{array}$ & $\begin{array}{c}9 \\
(90.0 \%) \\
\end{array}$ & 0.997 \\
\hline 2017 year & $\begin{array}{c}1 \\
(25.0 \%) \\
\end{array}$ & $\begin{array}{c}3 \\
(75.0 \%) \\
\end{array}$ & 0.997 \\
\hline 2016 year & $\begin{array}{c}1 \\
(14.3 \%) \\
\end{array}$ & $\begin{array}{c}6 \\
(85.7 \%) \\
\end{array}$ & 0.997 \\
\hline Personality & & & 0.997 \\
\hline \multicolumn{4}{|l|}{ Job Stressor } \\
\hline $\begin{array}{l}\text { Reporting \& } \\
\text { Communication } \\
(\mathrm{N}=16)\end{array}$ & $\begin{array}{c}2 \\
(14.3 \%)\end{array}$ & $\begin{array}{c}14 \\
(87.5 \%)\end{array}$ & 1,000 \\
\hline $\begin{array}{l}\text { CRRT } \\
(\mathrm{N}=9) \\
\end{array}$ & $\begin{array}{c}1 \\
(10.0 \%) \\
\end{array}$ & $\begin{array}{c}9 \\
(90.0 \%) \\
\end{array}$ & 1,000 \\
\hline $\begin{array}{l}\text { Echocardiography } \\
(\mathrm{N}=1)\end{array}$ & $\begin{array}{c}0 \\
(0 \%) \\
\end{array}$ & $\begin{array}{c}1 \\
(100 \%) \\
\end{array}$ & 1,000 \\
\hline $\begin{array}{l}\text { Intubation } \\
(\mathrm{N}=4)\end{array}$ & $\begin{array}{c}0 \\
(100 \%) \\
\end{array}$ & $\begin{array}{c}4 \\
(100 \%) \\
\end{array}$ & 1,000 \\
\hline $\begin{array}{l}\text { ABP } \\
(\mathrm{N}=1)\end{array}$ & $\begin{array}{c}0 \\
(0 \%) \\
\end{array}$ & $\begin{array}{c}1 \\
(100 \%) \\
\end{array}$ & 1,000 \\
\hline $\begin{array}{l}\text { Using Hazmat } \\
(\mathrm{N}=1)\end{array}$ & $\begin{array}{c}0 \\
(100 \%) \\
\end{array}$ & $\begin{array}{c}1 \\
(100 \%) \\
\end{array}$ & 1,000 \\
\hline $\begin{array}{l}\text { Heat and Well } \\
(\mathrm{N}=1)\end{array}$ & $\begin{array}{c}0 \\
(0 \%) \\
\end{array}$ & $\begin{array}{c}1 \\
(100 \%) \\
\end{array}$ & 1,000 \\
\hline
\end{tabular}

TABLE 8: Relationship Characteristics of the Subjects of Genesis Burnout on Post-ISOMAN

\begin{tabular}{|l|c|c|c|}
\hline \multirow{2}{*}{ Variable } & \multicolumn{3}{c|}{ Impression } \\
\cline { 2 - 4 } & Burnout & $\begin{array}{c}\text { Not } \\
\text { Burnout }\end{array}$ & p-Value \\
\hline Gender & & & 0.679 \\
\hline Age & & & 0.337 \\
\hline Marital status & & & 0.492 \\
\hline $\begin{array}{l}\text { PPDS Receipt } \\
\text { Year }\end{array}$ & & & \\
\hline 2019 year & $\begin{array}{c}0 \\
(0.0 \%)\end{array}$ & $\begin{array}{c}14 \\
(100 \%)\end{array}$ & 0.042 \\
\hline 2018 year & $\begin{array}{c}1 \\
(10.0 \%)\end{array}$ & $\begin{array}{c}9 \\
(90.0 \%)\end{array}$ & 0.249 \\
\hline 2017 year & $\begin{array}{c}1 \\
(25.0 \%)\end{array}$ & $\begin{array}{c}3 \\
(75.0 \%)\end{array}$ & 0.997 \\
\hline
\end{tabular}

\begin{tabular}{|c|c|c|c|}
\hline 2016 year & $\begin{array}{c}1 \\
(14.3 \%)\end{array}$ & $\begin{array}{c}6 \\
(85.7 \%) \\
\end{array}$ & 0.997 \\
\hline Personality & & & 0.997 \\
\hline \multicolumn{4}{|l|}{ Job Stressor } \\
\hline $\begin{array}{l}\text { Reporting \& } \\
\text { Communication } \\
(\mathrm{N}=16)\end{array}$ & $\begin{array}{c}2 \\
(14.3 \%)\end{array}$ & $\begin{array}{c}14 \\
(87.5 \%)\end{array}$ & 1,000 \\
\hline $\begin{array}{l}\text { CRRT } \\
(\mathrm{N}=9) \\
\end{array}$ & $\begin{array}{c}1 \\
(10.0 \%) \\
\end{array}$ & $\begin{array}{c}9 \\
(90.0 \%) \\
\end{array}$ & 1,000 \\
\hline $\begin{array}{l}\text { Echocardiography } \\
(\mathrm{N}=1)\end{array}$ & $0(0 \%)$ & $\begin{array}{c}1 \\
(100 \%)\end{array}$ & 1,000 \\
\hline $\begin{array}{l}\text { Intubation } \\
(\mathrm{N}=4)\end{array}$ & $\begin{array}{c}0 \\
(100 \%) \\
\end{array}$ & $\begin{array}{c}4 \\
(100 \%) \\
\end{array}$ & 1,000 \\
\hline $\begin{array}{l}\text { ABP } \\
(\mathrm{N}=1)\end{array}$ & $0(0 \%)$ & $\begin{array}{c}1 \\
(100 \%)\end{array}$ & 1,000 \\
\hline $\begin{array}{l}\text { Using Hazmat } \\
(\mathrm{N}=1)\end{array}$ & $\begin{array}{c}0 \\
(100 \%) \\
\end{array}$ & $\begin{array}{c}1 \\
(100 \%) \\
\end{array}$ & 1,000 \\
\hline $\begin{array}{l}\text { Heat and Well } \\
(\mathrm{N}=1)\end{array}$ & $\begin{array}{c}0 \\
(0 \%)\end{array}$ & $\begin{array}{c}1 \\
(100 \%)\end{array}$ & 1,000 \\
\hline
\end{tabular}

\section{DISCUSSION}

Based on the results of observations of the stages of RIK and burnout activities, data on Pre-RIK incidence of burnout occurred in 3 people or $8.57 \%$, followed by no burnout as many as 32 people. In Post-RIK, the incidence of burnout occurred in 3 people or $8.57 \%$, followed by no burnout by 32 people. In Post-ISOMAN, the incidence of burnout occurred in 1 person or $2.85 \%$ and 34 people did not burnout. Based on these data it can be concluded that the incidence of burnout in this study sample was very small. This is related to the role of the department of anesthesia and intensive therapy to anticipate the workload due to the pandemic COVID-19 (Sumner \& Kinsella, 2021).

The strategies applied such as the PPDS Anesthesiology and Intensive Therapy Dr. Soetomo was given more rest time than before the pandemic. This can be seen from the decrease in the incidence of burnout where when the residents were given time to "rest" at the ISOMAN stage, the burnout incidence rate was only $2.85 \%$ compared to the Pre-RIK and Post-RIK events which reached $8.57 \%$.

This is in line with the research conducted by Dimitriu et al where changing the rotation in work from 14 consecutive days to 7 days and giving weekend breaks has the effect of reducing burnout (Dimitriu et al., 2020). The amount of workload is considered not to have a consistent relationship with burnout, but working hours have a consistent relationship with burnout, for example, residents find it difficult to manage schedules and rapid patient turnover has a relationship with burnout (Hu et al., 2020).

When viewed based on the level of education, it was found that PPDS participants based on the year of acceptance of burnout in the Pre-RIK stage, there was 1 person or $14.3 \%$ burnout in the 2019 admission year and the non- burnout group was 6 people, 85.7\%. In the Post-RIK stage, data was obtained where the incidence of burnout in the year PPDS 2019 was received was 1 person or $14.3 \%$ and the group did not burnout 6 people or $85.7 \%$.

In the Post-ISOMAN stage, data was obtained where the incidence of burnout in the year PPDS 2019 received 1 person or $14.3 \%$ burnout and the group did not burnout 6 people or $85.7 \%$. In the PPDS acceptance in 2018 at the pre-RIK stage, 1 person or $7.1 \%$ burnout and 13 people or 92.9\% did not get burnout. In Post-RIK, 1 person has $7.1 \%$ burnout and 13 people have no $92.9 \%$ burout. 
At Post-ISOMAN, none of them experienced burnout.

PPDS received in 2017 at the Pre-RIK stage did not find any burnout incidents.

In Post-RIK, no burnout incident has been found. At PostISOMAN, none of them experienced burnout. PPDS acceptance in 2016 in the Pre-RIK stage, there was an incidence of burnout in 1 person or $25 \%$ and $75 \%$ of 3 people there was no burnout. In Post-RIK, there was an incidence of burnout in 1 person or $25 \%$ and $75 \%$ of 3 people there was no burnout. At Post-ISOMAN, none of them experienced burnout.

In the Post-ISOMAN analysis, there was a relationship between the length of education and burnout. The first year of frontline health workers are experiencing burnout, compared to the year-end, due to the non accustomed with the busy schedule of the hospital dring pandemic (Vassos et al., 2019). Study by Tan et al h is almost similar to research that has been carried out where the incidence of burnout syndrome was higher in PPDS participants who underwent their first year of education (Tan et al., 2020).

Based on the data obtained, it was found that personality type $\mathrm{A}$ in the Pre-RIK stage obtained 3 PPDS or $14.3 \%$ burnout where the group did not experience burnout of 18 PPDS or $85.7 \%$. In personality type B, in the Pre-RIK stage, there was no PPDS who experienced burnout. At the Post-RIK stage, there were 3 PPDS or $14.3 \%$ burnout, where the group did not experience burnout of 18 PPDS or $85.7 \%$.

In personality type $\mathrm{B}$, at the Post-RIK stage, there was no PPDS who experienced burnout. In the Post-ISOMAN stage, 1 PPDS or $4.8 \%$ occurred burnout where the group did not experience burnout by 20 people or $95.2 \%$. In personality type B, at the Pro-ISOMAN stage, there were no PPDS who experienced burnout. From the analysis of the relationship between personality and the incidence of burnout in PreRIK, Post-RIK, and Post-ISOMAN, it was found that there was no statistical relationship between personality and the incidence of burnout.

In the image data stressor PPDS against burnout at Pre-RIK obtained the data which the stressor reporting and communications reported 16 PPDS in which 14 or $87.5 \%$ of people in the group do not burnout and 2 or $14.3 \%$ in the burnout, followed by CRRT in the group do not burnout as much 9 people, Echocardiography 1 person, intubation 4 people, using hazmat 1 person, heat 1 person, and all reported in the no burnout group.

In handling COVID-19 patients in special isolation rooms, of course, some stressors can trigger fatigue or burnout (Dimitriu et al., 2020). In this study, it was found that the highest stressors were reporting and communication which reached $87.5 \%$. This is following research conducted by Zhang et al regarding the handling of COVID-19 patients in intensive rooms where burnout is related to communication problems, especially with superiors who are the main person in charge (Zhang et al., 2020).

In the residency phase, the PPDS Anesthesiology and Intensive Therapy Dr. Soetomo has two roles, namely to provide services, and the professional education program participants. $\mathrm{H}$ al this can lead to a problem where on one hand the participants' PPDS is still in the process of learning, so that mistakes and incompetence became things that should be tolerated. But, unlike the case of the task in the provision of services where such activities are required to not make errors in service efforts (Duarte et al., 2020).
In another study conducted by Barello et al that the relationship between doctors and nurses has a consistent role in job satisfaction. Several surveys have shown that the conflicted relationship between nurses, doctors, coworkers, colleagues, or superiors has a relationship with the risk of burnout (Barello et al., 2020). This mismatch has triggered problems in communication between the doctor in charge of PPDS.

Problems related to communication are a big challenge in a pandemic, a policy is needed, especially for the residency education process, because this has an impact on the incidence of fatigue or burnout (Sumner \& Kinsella, 2021).

There is a need for efforts to find a middle ground in communication and reporting so that comfort in the education process and service provision can be carried out optimally, especially during a pandemic where this incident is an extraordinary event that has major implications.

This is also illustrated in a study conducted by Sultana et al, where interpersonal conflicts inpatient care between doctors, nurses, and the doctor in charge of the main responsible cause moral pressure (Sultana et al., 2020). The inability of a doctor in charge to act according to internal and external values is also associated with the incidence of burnout. The importance of demonstrating healthy and positive collaboration can reduce the incidence of burnout (Duarte et al., 2020).

In the PPDS stressor description data on burnout in PostRIK, data was obtained where reporting and communication stressors were reported as 16 people, where 14 or $87.5 \%$ of people in the burnout group did not and 2 or $14.3 \%$ in the burnout group, followed by CRRT in the burnout group as many 9 people, Echocardiography 1 person, intubation 4 people, using hazmat 1 person, heat and stifling 1 person, and all reported in the no burnout group.

In the PPDS stressor image data on burnout in PostISOMAN, data was obtained where reporting and communication stressors were reported by 16 people, followed by CRRT in the non- burnout group of 10 people, Echocardiography 1 person, intubation 4 people, using 1 hazmat 1 person, heat and 1 people, and everything was reported in the no burnout group. Based on statistical analysis, there was no significant difference between job stressors and burnout events in PPDS Anesthesiology and Intensive Therapy. Soetomo at the Pre-RIK, Post-RIK and Post-ISOMAN stages.

\section{CONCLUSION}

Based on the results of the study above, it can be concluded that the percentage of burnout on the front line of health workers in the Anesthesiology and Intensive Therapy at the Hospital Dr. Soetomo is 3 people (9.37\%) and not burnout 32 people ( $90.63 \%$ ). In Post-RIK, there were 3 people with a burnout of $9.37 \%$ and no burnout of 32 people or $90.63 \%$. In Post-ISOMAN, there was 1 burnout or $2.85 \%$ and no burnout of 34 people or $97.15 \%$. The risk factors that influence the incidence of burnout in PPDS Anesthesiology and Intensive Therapy at RSUD Dr. Soetomo in dealing with COVID-19 in a special isolation room based on data and statistical significance is that the PPDS reception year in 2019 experienced more burnout, compared to the last year's PPDS. 


\section{REFERENCES}

[1] Barello, S., Palamenghi, L., \& Graffigna, G. (2020). Burnout and somatic symptoms among frontline healthcare professionals at the peak of the Italian COVID-19 pandemic. Psychiatry Research, 290, 113129.

[2] Dimitriu, M. C. T., Pantea-Stoian, A., Smaranda, A. C., Nica, A. A., Carap, A. C., Constantin, V. D., Davitoiu, A. M., Cirstoveanu, C., Bacalbasa, N., \& Bratu, O. G. (2020). Burnout syndrome in Romanian medical residents in time of the COVID-19 pandemic. Medical Hypotheses, 144, 109972.

[3] Duan, C., Talbott, E. O., Broadwin, R., Brooks, M., Matthews, K., \& Barinas-Mitchell, E. (2019). Residential Exposure to PM2. 5 and Ozone and Progression of Subclinical Atherosclerosis Among Women Transitioning Through Menopause: The Study of Women's Health Across the Nation. Journal of Women's Health.

[4] Duarte, I., Teixeira, A., Castro, L., Marina, S., Ribeiro, C., Jácome, C., Martins, V., Ribeiro-Vaz, I., Pinheiro, H. C., \& Silva, A. R. (2020). Burnout among Portuguese healthcare workers during the COVID-19 pandemic. BMC Public Health, 20(1), 1-10.

[5] Gu, J.-A., Choi, A.-S., \& Kim, H.-G. (2019). Applying the Havruta Learning Method to Nursing Education. Medico-Legal Update, 19(1), 653-658.

[6] Hu, D., Kong, Y., Li, W., Han, Q., Zhang, X., Zhu, L. X., Wan, S. W., Liu, Z., Shen, Q., \& Yang, J. (2020). Frontline nurses' burnout, anxiety, depression, and fear statuses and their associated factors during the COVID-19 outbreak in Wuhan, China: A large-scale cross-sectional study. EClinicalMedicine, 24, 100424.

[7] Matsuo, T., Kobayashi, D., Taki, F., Sakamoto, F., Uehara, Y., Mori, N., \& Fukui, T. (2020). Prevalence of health care worker burnout during the coronavirus disease 2019 (COVID-19) pandemic in Japan. JAMA Network Open, 3(8), e2017271-e2017271.

[8] Movlavi, S., \& Salehi, S. (2019). Examining the effect of implementation of the nursing process on students' health behaviors. International Journal of Adolescent Medicine and Health.
[9] Prabowo, H., Syafri, W., \& Juanda, J. (2020). PANDEMIC AT THE POLLS: PREPAREMENT AND ARRANGEMENT OF INDONESIAN REGIONAL THE ELECTION IN THE MIDST OF COVID-19. International Journal of Management (IJM), 11(12).

[10] Sultana, A., Sharma, R., Hossain, M. M., Bhattacharya, S., \& Purohit, N. (2020). Burnout among healthcare providers during COVID-19 pandemic: Challenges and evidence-based interventions.

[11] Sumner, R. C., \& Kinsella, E. L. (2021). Grace Under Pressure: Resilience, Burnout, and Wellbeing in Frontline Workers in the United Kingdom and Republic of Ireland During the SARS-CoV-2 Pandemic. Frontiers in Psychology, 11, 3757.

[12] Tan, B. Y. Q., Kanneganti, A., Lim, L. J. H., Tan, M., Chua, Y. X., Tan, L., Sia, C. H., Denning, M., Goh, E. T., \& Purkayastha, S. (2020). Burnout and Associated Factors Among Health Care Workers in Singapore During the COVID-19 Pandemic. Journal of the American Medical Directors Association, 21(12), 1751-1758.

[13] Tziomalos, K., Dimitriou, P., Bouziana, S. D., Spanou, M., Kostaki, S., Angelopoulou, S.-M., Papadopoulou, M., Giampatzis, V., Savopoulos, C., \& Hatzitolios, A. I. (2017). Stress hyperglycemia and acute ischemic stroke in-hospital outcome. Metabolism, 67, 99-105.

[14] Vassos, M., Nankervis, K., Skerry, T., \& Lante, K. (2019). Can the job demand-control-(support) model predict disability support worker burnout and work engagement? Journal of Intellectual \& Developmental Disability, 44(2), 139-149.

[15] Wardhana, A. K. (2020). Should be halal? is there any correlation between halal and vaccine? bibliography study in SCOPUS indexed academic paper. Journal of Halal Product and Research (JHPR), 3(2), 80-87.

[16] Żemojtel-Piotrowska, M., Piotrowski, J. P., Osin, E. N., Cieciuch, J., Adams, B. G., Ardi, R., Bălțătescu, S., Bogomaz, S., Bhomi, A. L., \& Clinton, A. (2018). The mental health continuum-short form: The structure and application for cross-cultural studies-A 38 nation study. Journal of Clinical Psychology, 74(6), 10341052.

[17] Zhang, Y., Wang, C., Pan, W., Zheng, J., Gao, J., Huang, X., Cai, S., Zhai, Y., Latour, J. M., \& Zhu, C. (2020). Stress, burnout, and coping strategies of frontline nurses during the COVID-19 epidemic in Wuhan and Shanghai, China. Frontiers in Psychiatry, 11, 1154. 